\title{
AS PESQUISAS SOBRE CICLOS DE VIDA PROFISSIONAL DOCENTE: REVISÃO DA LITERATURA
}

\author{
Investigación acerca del ciclo de vida profesional: revisión de literatura
}

Research on teacher's professional life cycles: systematic review

Kátia Augusta Curado Pinheiro Cordeiro da Silva*

Shirleide Pereira da Silva Cruz**

https://doi.org/10.38117/2675-181X.formov2020.v2i2n4.439-458

\section{RESUMO}

$\mathrm{O}$ artigo tem o objetivo de analisar as publicações no Brasil que tratam dos ciclos de vida profissional na carreira docente como um processo de vivências na profissão que oportunizam movimentos de profissionalizaçao. A metodologia utilizada foi o estudo bibliográfico, tendo como referência o levantamento nas bases de dados: a SciELO, o Instituto Brasileiro de Informação em Ciência e Tecnologia (Ibict), a Associação Nacional de Pós-graduação e Pesquisa em Educação (ANPEd) e a Coordenação de Aperfeiçoamento de Pessoal de Nível Superior (CAPES), além da ferramenta de busca Google Acadêmico. A partir da pesquisa, foram selecionadas as produções de 2006 a 2019 e encontrados um total 15 de artigos, 3 teses e 3 dissertações. Os estudos revisados apontam que os ciclos de vida profissional na carreira dos docentes são estudados a partir da literatura internacional, principalmente em Huberman (2000), cujo enfoque maior é sobre a fase de inserção na carreira, assinalando que existem etapas comuns nas trajetórias dos profissionais, tendo como referência a temporalidade da carreira. A investigação aponta para a necessidade de estudar especificamente o ciclo de vida profissional no Brasil, a partir da categoria do trabalho docente aliada às especificidades da história pessoal de cada professor.

PALAVRAS CHAVE: Formaçao de professores; Ciclo de vida profissional; Estado do conhecimento. 


\section{RESUMEN}

El artículo tiene como objetivo analizar publicaciones en Brasil que aborden los ciclos de vida profesional en la carrera docente como un proceso de experiencias en la profesión que proporciona movimientos de profesionalización. La metodología utilizada fue el estudio bibliográfico, teniendo como referencia la revisión de la literatura y como bases de datos el SciELO, el Instituto Brasileño de Información en Ciencia y Tecnología (Ibict), la Asociación Nacional de Estudios de Posgrado e Investigación en Educación (ANPEd) y la Coordinación para la Mejora del Personal de Educación Superior (CAPES), además de la herramienta de búsqueda Google Académico. De la investigación, fueron seleccionadas producciones de 2006 a 2019 y encontrado un total de 15 artículos, 3 tesis y 3 disertaciones. Los estudios revisados señalan que los ciclos de vida profesional en la carrera de los profesores son estudiados a partir de la literatura internacional, principalmente en Huberman (2000), cuyo enfoque principal está en la fase de inserción en la carrera, señalando que hay etapas comunes en las trayectorias de los profesionales, teniendo como referencia a la temporalidad de la carrera profesional. La investigación apunta a la necesidad de estudiar específicamente el ciclo de vida profesional en Brasil, basado en la categoría de trabajo docente combinada con las especificidades de la historia personal de cada maestro.

PALABRAS CLAVE: Formación del profesorado; Ciclo de vida profesional; Revisión de literatura.

\section{ABSTRACT}

The article aims to analyze publications in Brazil that deal with the cycles of professional life in the teaching career as a process of job experiences that provide opportunities for professionalization movements. The methodology used was the bibliographic study referenced in SciELO databases, the Brazilian Institute of Information in Science and Technology (Ibict), the National Association of Graduate Studies and Research in Education (ANPEd) and the Coordination for the Improvement of Higher Education Personnel (CAPES) and the search tool Academic Google. Then, we selected the production from 2006 to 2019, in 15 articles, 3 theses and 3 dissertations. The reviewed studies point out that the professional life cycles of the teachers' career are studied from the international literature, mainly Huberman (2000), whose major focus is on the career insertion phase, pointing out that there are common stages in the trajectories of professionals with reference to career temporality. We point to the need of research that investigates the professional life cycle in Brazil with the specificities of each teacher's personal history.

KEYWORDS: Teacher education; Professional life cycle; Literature review. 


\section{Introdução}

Os estudos do ciclo de vida profissional docente, especificamente de Tardif (2000) e Huberman (2000), concebem a carreira docente como um processo de socialização e incorporação na atividade profissional, de modo a apresentar variações de acordo com o tempo e a função a ser desempenhada, cuja carreira é marcada por vários acontecimentos que se tornam marcos na trajetória docente.

Um dos modelos mais referenciados sobre os ciclos de vida profissional de docentes é aquele elaborado por Huberman (2000), cuja classificação foi construída a partir da leitura e análise de estudos empíricos. A sistematização considera os anos de docência dos professores e apresenta algumas características próprias de cada fase vivenciada durante o percurso profissional: fase de entrada na carreira (1 a 3 anos de docência); fase de estabilização ( 4 a 6 anos); de diversificação ( 7 a 25 anos); de serenidade (25 a 35 anos); e fase de desinvestimento (mais de 35 anos de docência). De maneira similar e a partir de pesquisa com professores, outros autores apontam para o ciclo da carreira profissional sistematizando-o em fases que não são estáticas, entretanto, marcadas pela temporalidade. São exemplos desses estudos os de Gonçalves (1992), Stroot (1996), Barone et al. (1996) e Nascimento; Graça (1998).

Depreende-se que a dimensão temporal ganha relevância nos estudos que configuram a carreira docente. Contudo, questiona-se se, além do tempo de carreira, há outros fatores que se relacionam ao trabalho de modo a garantir a consolidação do desenvolvimento e da profissionalização docente, alinhando princípios que norteiem o reconhecimento das especificidades do exercício do magistério e as condições reais e objetivas daqueles que realizam o seu trabalho.

Nesse contexto, foi levantado o objetivo numa pesquisa mais ampla o de questionar como se constrói o ciclo de vida profissonal no Distrito Federal, tendo como dimensões a temporalidade e a condição do trabalho docente, entendendo que tais condicionalidades podem gerar diferentes categorias que permeariam e explicariam o ciclo de vida docente, tais como: satisfação/insatisfação; sofrimento/prazer; desistência/permanência; envolvimento com a profissão (como investe na carreira e profissão); envolvimento com a escola (sentido político da escola como lócus do trabalho). Neste trabalho apresentaremos a primeira parte da pesquisa referente ao Estado do Conhecimento com o recorte temporal de 2006 a 2019. 


\section{Ciclo de carreira docente, desenvolvimento profissional, desenvolvimento profissional e perejivânie: escolhas teórico-metodológicas}

Ao eleger a temática de estudo, optou-se pelo recorte do ciclo de carreira docente; entretanto, ao aprofundar no tema, adveio a oportunidade de verificar que existem diversas formas conceituais não apenas de organizar o ciclo de vida profissional, mas também de significados dos conceitos que são designados para abordar a temática da vivência profissional, sendo os principais: ciclo de carreira docente; trajetória profissional; e desenvolvimento profissional. Nesse sentido, fazendo recortes, foi possível a aproximação do conceito de ciclo da vida profissional, reelaborado com a compreensão da categoria vygotskiana de perejivânie (vivência). A seguir, apresenta-se essa aproximação e/ou distanciamento dos conceitos.

O termo ciclo de carreira docente tem diversos significados, o que dá à expressão uma difícil definição, mas se aproxima da possibilidade de progressão no processo de profissionalização. Assim, no geral, a carreira pode designar uma mobilidade ocupacional, referindo-se a um caminho a ser trilhado por um profissional. Destaca-se, de acordo com Martins (2001), que o conceito da carreira tradicional tem dois aspectos centrais: o primeiro deles é a noção de progressão vertical na hierarquia de uma organização, acompanhada de ganhos financeiros; e o segundo é a pressuposição de uma carreira estável, em que o indivíduo exerceria suas atividades profissionais em uma única empresa, até a sua aposentadoria.

Portanto, quando se trabalha com o conceito de ciclo da carreira, este é marcado pela progressão ao longo das fases que o compõem, a saber, um estágio inicial, que é o momento da busca por uma carreira; os estágios intermediários, de construção e desenvolvimento da vida profissional; e um estágio final que é o término da carreira. Contudo, a proposta da pesquisa é questionar se, além do tempo de carreira, há outros fatores que se relacionam ao trabalho de modo a garantir a consolidação do desenvolvimento e profissionalização docente, alinhando princípios que norteiem o reconhecimento das especificidades do exercício do magistério e as condições reais e objetivas daqueles que realizam o seu trabalho.

O conceito de desenvolvimento profissional docente é bastante recente e vem progredindo significativamente a partir da década de 1980. O conceito "desenvolvimento" apresenta uma conotação de evolução e continuidade que supera a justaposição tradicional existente entre a formação inicial e contínua dos professores. Por outro lado, decorre do reconhecimento de que o desenvolvimento profissional não pode ser imposto, mas deve estar sob a responsabilidade do professor que precisa querer investir na profissão (MARCELO GARCIA, 2009), elemento que vem sendo assumido nas políticas de formação, acarretando uma responsabilização individual do professor e desresponsabilizando o Estado quanto à unidade formação inicial e continuada. 
As múltiplas definições marcam o desenvolvimento profissional docente como um processo individual ou coletivo, preferencialmente localizado no ambiente de atuação do docente, ou seja, na escola, e tendo as seguintes características: i) é baseado no construtivismo; ii) o processo ocorre a longo prazo; iii) as experiências são mais eficazes se forem baseadas na escola e relacionadas com as atividades diárias dos professores; iv) está diretamente relacionado aos processos de reforma da escola; v) o professor adquire mais conhecimento a partir da reflexão sobre as experiências; vi) o processo é colaborativo; e vii) são diferentes as formas em diferentes contextos (MARCELO GARCIA, 2009).

Não se pode prescindir da importância do conceito para a formação de professores e, embora esteja marcado pela crítica da ênfase no desenvolvimento e, portanto, na perspectiva individual, é uma compreensão que permite a unidade da formação num contínuo desde a pré-formação, a formação inicial e a continuada. Nesse processo contínuo de tornar-se professor, os docentes se desenvolvem profissionalmente, considerando os desafios e as exigências da sociedade e também as especificidades que marcam o segmento de ensino no qual atua. Portanto, o conceito corrobora para que se compreenda a vivência profissional docente, marcada por exigências pessoais, profissionais, organizacionais, contextuais, psicológicas, específicas e diferenciadas. Contudo, o estudo do tema tem apontado para a necessidade de uma categoria que exprima a dialética do trabalho docente sem estar formatada pela linha do desenvolvimento.

Huberman (2000) e diferentes autores como Gonçalves (1992); Stroot (1996); Barone et al. (1996); e Nascimento e Graça (1998) procuram discorrer sobre o ciclo de vida profissional, entendido como o percurso profissional marcado por etapas e fases, com o recorte do tempo como uma das suas principais marcas. Assim, tais estudos buscam compreender e caracterizar o professor em cada um de seus estágios de vida profissional. Ao construir uma teorização dos ciclos profissionais docentes, Huberman (2000) deixa claro que nem todos os professores vivenciam sequencialmente as mesmas fases e nem todos passam por todas elas. O professor, ao longo da carreira, passa por processos diferenciados e peculiares que podem ser caracterizados por fases da trajetória profissional.

A opção do GEPFAPe foi por estudar o ciclo vida profissional observando as marcas singulares do trabalho docente que trazem o trabalho como constituição do ser docente. Tais marcas são aqui delineadas pelas seguintes questões: a forma de operacionalização da atividade docente; a questão de gênero, classe e etnia, idade e tempo de docência; o ingresso na carreira por concurso; a entrada na rede e as formas de sua recepção na/pela instituição; valorização social e material; dentre outras. Compreende-se que essas são marcas singulares que incidem no ciclo de vida profissional a partir da materialidade do trabalho docente. 
Nesse sentido, nos aproximamos do conceito de perejivânie (vivência) que ainda é pouco estudado no Brasil, sendo apontado por Vygotsky (2010) como o significado capaz de explicar o desenvolvimento da consciência humana na relação com o meio social. Segundo esse autor, a perejivânie sempre remete a algo que impacta o sujeito, que o transforma, que o modifica e, portanto, modifica sua relação com dada realidade e, assim, podemos eleger as marcas do ciclo de vida profissional e nem tanto suas fases. Quando um sujeito passa por situação de perejivânie (vivência), nada mais continua igual; sua atitude muda em relação à situação vivida, passando a ter outra relação com o objeto pelo qual foi afetado na situação social. Dessa forma, vão se construindo não apenas ciclos, mas um movimento espiral - com um aparente ordenamento interno mas que se constrói num caos que integra todo o ser humano.

As vivências são fonte de afetos, portanto, medeiam a produção de sentidos que constituem modos particulares de ser, pensar e agir dos homens; representam a unidade essencial e constitutiva, pois é a unidade que explica o desenvolvimento como resultado de convergências e confrontos vivenciados nas relações sociais e materiais da vida. Segundo Vygotsky (2010), a categoria perejivânie ajuda a explicar que o desenvolvimento da consciência é processo, ao mesmo tempo racional e afetivo, ligado à vida real das pessoas, ou seja, à própria existência. As vivências englobam tanto a tomada de consciência quanto a relação afetiva com o meio, e da pessoa consigo mesma, pela qual se dispõem, na atividade consciente, a compreensão dos acontecimentos e a relação afetiva com eles (VYGOTSKI, 2010). Assim, embora não seja abandonado o conceito de ciclo de vida profissional, há uma aproximação da categoria perejivânie, pois esta possibilita enxergar os fenômenos da existência humana, aqui especificamente, da vida profissional, o processo que os gera.

\section{Metodologia}

O Estado do Conhecimento é um instrumento metodológico para a construção do objeto de pesquisa. Entende-se que é de grande relevância ler o que já foi escrito ou pensado sobre o tema proposto na pesquisa, e sondar os domínios teóricos que podem esclarecer questões relativas ao objeto a ser estudado. O recorte temporal de 2006 a 2019 se justifica por contemplar a última década, considerando que, desde 1990, a temática tem sido analisada e os estudos bibliográficos datam, portanto, desse período anterior.

Para tanto, procedeu-se com a pesquisa e o refinamento dos dados nas seguintes bases de dados: Biblioteca de Teses e Dissertações (BDTD) do Instituto Brasileiro de Informação em Ciência e Tecnologia (IBICT) e da Capes; Anais de Eventos de ampla participação na pesquisa da área de educação, como Anped, Endipe, Anpae e Educere; Redes de pesquisa relacionadas à política educacional e ao trabalho docente, como Rede Latino-Americana de Estudos sobre Trabalho Docente (Rede Estrado), Rede de Estudos 
e Pesquisas sobre Implementação de Políticas Educacionais (REIPPE) e Red de Estudios Teóricos y Epistemológicos em Política Educativa (ReLePe); Scielo; Google Acadêmico.

Nessas bases, foram utilizados como descritores e/ou palavras-chave as seguintes expressões: ciclo de vida profissional; ciclo de carreira dos professores; ciclo carreira docente; ciclo de carreira docente; ciclo de vida dos professores; e ciclo profissional docente. Dessas expressões, apenas duas não geraram a localização de trabalhos, a saber: ciclo de carreira dos professores e ciclo de vida de professores. A partir da busca, procedeu-se com a leitura, primeiramente, uma leitura flutuante dos trabalhos e depois uma leitura buscando construir eixos de análise. Foram encontrados 21 trabalhos que versam sobre o ciclo de vida profissional que estão apresentados no Quadro 2.

Quadro 2 - Trabalhos localizados por ano, título e tipo

\begin{tabular}{|c|c|c|}
\hline ANO & TRABALHO LOCALIZADO & TIPO \\
\hline 2007 & $\begin{array}{l}\text { 1-ISAIA, BOLZAN, GIORDANI. Movimentos construtivos da docência } \\
\text { superior: delineando possíveis ciclos de vida profissional. }\end{array}$ & Evento ( Anped) \\
\hline \multirow{3}{*}{2008} & $\begin{array}{l}\text { 2-FELLER. Processos formativos e ciclo de vida de uma professora } \\
\text { alfabetizadora. }\end{array}$ & Dissertação (UFSM) \\
\hline & $\begin{array}{l}\text { 3-ISAIA; BOLZAN. Compreendendo os movimentos construtivos da } \\
\text { docência superior: construções sobre pedagogia universitária }\end{array}$ & Revista Linhas Críticas (B2) \\
\hline & $\begin{array}{l}\text { 4-BUSS et al. Marcadores da trajetória docente de professores de uma IES } \\
\text { pública: sinais da vida e da profissão. }\end{array}$ & $\begin{array}{ll}\text { Evento } & \text { (Redestrado- } \\
\text { Argentina) } & \\
\end{array}$ \\
\hline \multirow{2}{*}{2009} & $\begin{array}{l}\text { 5-BIASOLI. Docência em artes visuais: continuidades e descontinuidades na } \\
\text { (re)construção da trajetória profissional. }\end{array}$ & Tese ( UFPel) \\
\hline & $\begin{array}{l}\text { 6-ISAIA; CASTRO. Professores de uma IES pública e de uma IES } \\
\text { confessional: Comparando trajetórias docentes. }\end{array}$ & Revista VIDYA (A2) \\
\hline 2010 & $\begin{array}{l}\text { 7-ISAIA, et. al. Ciclos de vida profissionais de docentes do ensino superior: } \\
\text { identificação preliminar de movimentos construtivos }\end{array}$ & Relatório de Pesquisa \\
\hline 2011 & $\begin{array}{l}\text { 8-BRITO. O ciclo de vida profissional dos professores de biologia da } \\
\text { Universidade Federal de Uberlândia: trajetórias, carreira e trabalho. }\end{array}$ & Tese (UFU) \\
\hline 2012 & $\begin{array}{l}\text { 9-ROSSI; HUNGER. As etapas da carreira docente e o processo de formação } \\
\text { continuada de professores de Educação Física. }\end{array}$ & $\begin{array}{l}\text { Revista Brasileira de Educ. } \\
\text { Física e Esporte (B1) }\end{array}$ \\
\hline \multirow{2}{*}{2015} & $\begin{array}{l}\text { 10-GODTSFRIEDT. Ciclos de vida profissional na carreira docente: revisão } \\
\text { sistemática da literatura }\end{array}$ & $\begin{array}{l}\text { Revista Corpoconsciência } \\
\text { (B5) }\end{array}$ \\
\hline & $\begin{array}{l}\text { 11-RIBEIRO; VIEIRA. Ciclo de vida profissional e a formação continuada } \\
\text { dos Professores das instituições privadas de ensino superior em Curitiba. }\end{array}$ & Evento (Educere) \\
\hline 2016 & $\begin{array}{l}\text { 12-PIRES; ALVES; GONÇALVES. Desenvolvimento profissional docente: } \\
\text { percepções dos professores em diferentes períodos ao longo da vida. }\end{array}$ & $\begin{array}{ll}\text { Revista Portuguesa } & \text { de } \\
\text { Pedagogia- Lisboa (B3) } & \end{array}$ \\
\hline \multirow{5}{*}{2017} & $\begin{array}{l}\text { 13-GARBIN. A prática pedagógica de professores em diferentes momentos } \\
\text { da carreira }\end{array}$ & Dissertação ( PUC-PR) \\
\hline & $\begin{array}{l}\text { 14-FERREIRA. Desenvolvimento profissional e carreira docente: diálogos } \\
\text { sobre professores iniciantes }\end{array}$ & $\begin{array}{lll}\begin{array}{l}\text { Revista } \\
\text { (A2) }\end{array} & \text { Acta } & \text { Scientiarum } \\
\end{array}$ \\
\hline & $\begin{array}{l}\text { 15-CARDOSO. Ciclo de carreira docente: } \mathrm{O} \text { que dizem as pesquisas } \\
\text { brasileiras? }\end{array}$ & Evento (Educere) \\
\hline & $\begin{array}{l}\text { 16-FONTANINI; FILIPAK; KRAST. As fases na vida dos professores: um } \\
\text { estudo com professores do curso de administração em uma instituição de } \\
\text { educação superior privada no brasil. }\end{array}$ & $\begin{array}{ll}\text { Revista } & \text { ESPACIO- } \\
\text { Venezuela (B2) } & \end{array}$ \\
\hline & $\begin{array}{l}\text { 17-TIMM. O ciclo de vida profissional na docência no stricto sensu em } \\
\text { educação: o sentido, o significado e a percepção do bem/mal-estar a partir de } \\
\text { narrativas (auto)biográficas. }\end{array}$ & Tese (UFRGS) \\
\hline
\end{tabular}




\begin{tabular}{|l|l|l|}
\hline \multirow{5}{*}{2018} & $\begin{array}{l}\text { 18-PITTA. Razões que mobilizam o exercício docente nos anos iniciais da } \\
\text { educação básica }\end{array}$ & $\begin{array}{l}\text { Dissertação (Universidade } \\
\text { La Salle) }\end{array}$ \\
\cline { 2 - 3 } & $\begin{array}{l}\text { 19-ALVARENGA; TAUCHEN. Percepções e compreensões sobre o ciclo de } \\
\text { vida profissional e o desinvestimento da carreira docente. }\end{array}$ & $\begin{array}{l}\text { Revista Conhecimento } \\
\text { (B2) }\end{array}$ \\
\cline { 2 - 3 } & $\begin{array}{l}\text { 20-FARIAS; BATISTA; GRAÇA; NASCIMENTO. ciclos da trajetória } \\
\text { profissional na carreira docente em educação física. }\end{array}$ & $\begin{array}{l}\text { Revista Movimento } \\
\text { (A2) }\end{array}$ \\
\cline { 2 - 3 } & $\begin{array}{l}\text { 21-CARDOSO; SILVA; FRANÇA. O ciclo de carreira e as condições de } \\
\text { trabalho: aproximações e relações possíveis. }\end{array}$ & Evento (Endipe) \\
\hline
\end{tabular}

Fonte: As Autoras, (2020)

O Quadro 1 mostra insipiência no que tange à diversificação de Programas de Pósgraduação com pesquisas sobre a temática, visto existirem somente 5 programas distintos em todo Brasil e somente 6 trabalhos, entre teses e dissertações. Observa-se a presença maior de estudos publicados em revistas e eventos, 8 e 5, respectivamente. Essa característica parece indicar que algumas pesquisas estão ainda em andamento e tem apresentado seus dados parciais em artigos de menor porte, comparado ao volume teórico-metodológico próprio de teses e dissertações. Ao mesmo tempo, percebe-se que as pesquisas concluídas também puderam ser divulgadas em eventos e em revistas, agregando inclusive, outros autores e atualizações de análises. Essas últimas características serão melhor detalhadas quando da sistematização da produção identificada.

Outra observação pertinente é quanto ao extrato Qualis Capes das revistas nas quais as pesquisas foram publicadas, praticamente todos com classificação entre A2 e B5, correspondente ao Quadriênio 2012-2016, o que denota também ampla divulgação das pesquisas no que se refere à pesquisa educacional. Percebeu-se ainda que a Redestrado que tem como foco o trabalho docente - foi a única rede em que figurou a temática do ciclo de de vida profissional docente, mostrando-se importante canal para se consolidar estudos amplos em redes de pesquisas, em detrimento de outras redes que tem a temática da política educacional à qual se poderia articular a análise dos ciclos numa persepctiva de profissionalização em sua dimensão coletiva.

Uma primeira constatação obtida por meio do quadro-resumo indica que, embora pareça haver uma certa progressão temporal, como dito anteriormente, a produção é insipiente nos Programas de Pós-graduação. Observa-se ainda uma dispersão entre outras bases de dados; porém, os anos de 2017 e 2018 se mostraram bastante equivalentes quanto à distribuição de pesquisas em programas, revistas e eventos.

A partir de 2007, Isaia, Bolzan e Giordani iniciam uma ampla pesquisa sobre o tema que, ao longo do período estudado, foi se diversificando em termos de contexto e de perfil docente (ISAIA; BOLZAN, 2008; ISAIA, et al. 2010; ISAIA; CASTRO, 2009). Estas autoras e ainda Buss et al. (2015) tiveram foco no docente que atua no ensino superior e sem eleger, necessariamente, uma área de formação específica, seja bacharelado ou licenciatura. Sobre o ensino superior, também se destaca a presença 
significativa de estudos com foco em áreas específicas, como Biologia e Administração; e também no âmbito da Pós-graduação, com um total de 6 trabalhos. Contudo, é o contexto da educação básica que concentra o maior número das pesquisas encontradas, com destaque para os anos iniciais do ensino fundamental com 7 estudos; seguida do ensino médio e ensino fundamental, anos finais, direcionando-se mais para áreas determinadas de formação do que para a etapa de ensino em si, como é o caso das Artes Visuais e da Educação Física.

Em relação à localização geográfica dos estudos, identificou-se que a maioria foi produzida por pesquisadores da Região Sul do país, sendo que os demais trabalhos figuraram da Região Centro-Oeste, Sudeste e uma pesquisa internacional de um distrito de Lisboa.

De modo geral, a maioria expressiva dos estudos se baseou na abordagem do ciclo de vida profissional proposto por Huberman (2000); porém, boa parte deles dialogou com diferentes autores, tanto por conta da perspectiva teórico-metodológica eleita, como por já agregar elementos sistematizados de pesquisas já realizadas no contexto brasileiro, a exemplo dos estudos de Isaia, Bolzan, Giordani (2007) e seus colaboradores. Outro aspecto a se destacar está relacionado aos autores comumente mais utilizados, cujos referenciais trazem Nóvoa (2000), Gonçalvez Cruz (1998 apud FANTANINI; FILIPAK; KRAST, 2017) e Marcelo Garcia (2009) que também debatem a temática do ciclo.

Observou-se ainda a indicação de um número significativo de diferentes autores para a composição dos referenciais teóricos das pesquisas, dentre eles Riegel (1979), Stroot (1996), Josso (2004), Erickson (1993), Bosi (1994), e outros mais. Esse aspecto parece dizer respeito às possíveis aproximações dos estudos com outros campos das ciências humanas, tais como os da Psicologia, Sociologia, Antropologia e História. Isso traz a reflexão sobre como se torna necessário o olhar investigativo para o ciclo de vida profissional como algo complexo e dialético, em que se observa diferentes fatores e diferentes dimensões de análise, reconhecendo o processo de formação humana do qual o trabalho é um dos elementos constituintes para, assim, poder ser visto sob diferentes perspectivas.

Quanto à abordagem metodológica, os estudos se centraram mais em desenvolver entrevistas semiestruturadas a partir de narrativas em diferentes vertentes, como história oral temática, reconstrução autobiográfica, autobiografias etc. Esse aspecto endossa a indicação de que a maioria dos estudos localizados tomaram a análise do ciclo de vida profissional a partir das subjetividades dos professores, com destaque para as percepções e interpretações que os estes constroem sobre como se constituem enquanto professores em diferentes contextos. Assim também são destacadas algumas especificidades do trabalho em diferentes etapas de ensino, a exemplo das especificidades do ensino superior 
e da educação básica, tal como o ser professor dos anos iniciais do ensino fundamental, o ser professor de educação física etc.

Das características gerais dos estudos identificados, pôde-se avançar para a construção de eixos de análise que foram construídos a partir da leitura flutuante e da sistematização de convergências, direcionamentos diferentes e perspectivas de aprofundamento. Assim, foi possível elaborar três eixos de análise, a saber: i) abordagem bibliográfica; ii) análise processual do ciclo de vida profissional; iii) foco numa dimensão do ciclo. A seguir, está apresentada a discussão de cada um desses eixos.

O artigo de Godtsfriedt (2015) é um dos exemplos do eixo da abordagem bibliográfica. A partir da premissa de que os ciclos de vida profissional na carreira docente são reconhecidos como um processo de socialização e responsabilização da atividade profissional que os sujeitos realizam ao longo dos anos. A partir do critério de acessar trabalhos publicados entre os anos de 2004 e 2013 Godtsfriedt (2015), destaca que, embora os professores tenham diferentes formações e diferentes tempos e espaços de atuação, existem pontos em comum em suas trajetórias profissionais no campo da docência, respeitadas ainda as singularidades da história pessoal de cada professor.

Nessa mesma linha, Cardoso (2017), com o objetivo mais amplo de compreender as vivências profissionais de professoras da educação infantil no Distrito Federal, busca caracterizar a produção brasileira sobre o ciclo de vida profissional. Desta feita, destacase que, cronologicamente, a autora avança do recorte temporal da pesquisa anterior, contribuindo, portanto, com certa progressão na análise linear temporal dos estudos com a temática. A referida autora se debruça, portanto, em levantar na base de dados da Capes e da Anped, pesquisas brasileiras que tiveram como foco o ciclo de vida profissional. Assim, identifica que há uma predominância ao analisar o ciclo como um movimento marcado por etapas (início- estabilidade e fim), problematizando que a abordagem etapista pode invisibilizar aspectos muitos singulares dos professores que indicam formas outras de ver o processo de desenvolvimento e de vivência do ciclo pelos professores. Nesse contexto, apresenta uma noção de 'linhas de forças', a partir de Brito (2011), para indicar que, em momentos de transição, os professores se apoiam nessas linhas para prosseguir nas diferentes fases de sua vida profissional. De modo similar ao identificado por Godtsfriedt (2015), o levantamento realizado por Cardoso (2017) também chega à compreensão de que o ciclo é um processo invididual e coletivo, no qual os sujeitos vivenciam e sentem as fases da carreira de modo singular, a partir de um contexto social mais amplo. Silva (2018) no painel apresentado no Endipe também realizou estudo bibliográfico no contexto do Distrito Federal e indicou a ausência de estudos sobre a temática e destacou a pesquisa de Vargas (2016) que teve como foco a recepção do professor iniciante pelo gestor escolar. 
O último exemplo do eixo da abordagem bibliográfica é o estudo de Alvarenga e Tauchen (2018). Contudo, pode-se considerar que este também figura no eixo da eleição de uma dimensão sobre o ciclo, uma vez que, embora realize um levantamento bibliográfico, seu objeto de estudo é a compreensão de como os estudos tem focado a fase do desinvestimento proposto por Huberman (2000). Assim, em um momento inicial do texto, as autoras discorrem sobre os principais conceitos que nortearam suas análises, sendo o principal deles o conceito de auto-eco-organização, baseado em Morin (2005) e Pineau (2003), observando também aspectos analíticos gerais sobre os estudos do ciclo de vida profissional para, posteriormente, dar destaque aos aspectos próprios da fase de desinvestimento. Neste contexto, Alverenga e Tauchen (2018) fazem uma crítica à lógica binária de se analisar a fase de desinvestimento pela dimensão da seneridade versus amargura que caracterizaria tal fase, considerando que pode haver a possibilidade de transformação e de construção de novos ciclos mesmo num momento considerado como final da carreira. Assim o o desinvestimento pode se configurar no encerramento de um ciclo profissional em um dado tempo e espaço institucional, mas não significa que não se abram outras possibilidades para se pensar em outros projetos de vida para o professor.

O eixo da análise processual do ciclo de vida profissional pareceu o mais rico em termos de abordagem conceitual, embora no que tange ao aspecto metodológico tenha se concentrado mais numa abordagem pelo viés da subjetividade. Em relação ao aspecto teórico-conceitual, os estudos que seriam caraterizadores desse eixo, além de trazer para a divulgação científica estudos poucos referenciados no Brasil, avançam em alguns casos da indicação predominante de Huberman (2000); a exemplo da indicação de outras pesquisas que analisam o ciclo de vida profissional sob outros referenciais.

Esses estudos que analisaram o ciclo de vida como um processo em sua totalidade também apresentaram um conjunto de definiçõos pertinentes ao modo como o analisaram, indicando as principais definições dos conceitos eleitos dentro do referncial teórico. Exemplo desse aspecto está nos estudos desenvolvidos por Isaia e Bolzan (2007); Isaia et al. (2010); Isaia e Castro (2010), nos quais, progressivamente, a autora e os demais pesquisadores vão indicando definições, tais como o de carreira pedagógica equivalente à carreira docente. O mesmo aspecto está também na pesquisa de Buss, et al. (2008) para quem a carreira docente é entendida como um

[...] um processo que envolve a trajetória especificamente docente dos professores em uma ou em várias instituições de ensino, nas quais estiveram ou estão engajados e que, de algum modo, condiciona as ações formativas que eles realizam, tendo em vista o próprio desenvolvimento e de seus alunos. Desejos, sentimentos, expectativas emanados do entorno educativo e do mundo interior dos professores são responsáveis pela configuração que cada um pode apresentar em diferentes momentos da carreira docente. Assim, esta é influenciada, tanto pelas características pessoais (trajetória de vida) dos professores, 
quanto pelas profissionais (contexto institucional em que estão inseridos) (p. 6).

A respeito do próprio conceito de carreira, é preciso atenção para o fato de que embora a maioria dos estudos se utilizem do termo, geralmente não o apresenta de forma clara no conjunto total dos estudos localizados, sendo o de Buss et al. (2010) o que o define de modo mais claro. Já na investigação de França (2018), inserido no painel do Endipe, por Cardoso, Silva e França (2018), a abordagem do conceito de carreira é desenvolvida pela via da legislação enquanto elemento estruturado num plano composto por variáveis de remuneração e etapas que podem expressar valorização e desvalorização. Brito (2011) também analisou o ciclo de vida profissional tomando como referência a carreira do professor no ensino superior, numa tríade trabalho-sujeito-universidade. A autora partiu de uma definição de carreira por Morosini (2006, p. 402) que analisa o contexto específico do ensino superior, definindo-o pela forma como as instituições universitárias pensam e organizam a vida dos professores.

Outro conceito que também é muito comum ser encontrado em diferentes pesquisas localizadas é o de trajetória e, por conseguinte, o de trajetória docente. De modo similar à produção indicada em Buss et al. (2010), este também foi um dos estudos que indicou de forma clara o conceito de trajetória que, para as autoras, indica o percurso no qual a noção de tempo, de duração e de finitude estão envolvidos. A trajetória docente envolveria, portanto, uma integração tanto da dimensão pessoal quanto profissional, circunscritas em porções de tempo não lineares, mas que entrelaçam fases, idades e etapas, convivendo numa mesma duração (BUSS, et al., 2010). A partir de Ortega y Gasset (1955) as autoras também se norteiam pela noção de geração pedagógica entendida como" [...] um conjunto de professores que se situam em uma mesma dimensão temporal e compartilham, entre si, valores, crenças, convicções e estilos próprios de entender e viver a docência".

Outros conceitos ainda foram pertinentes para as análises e por meio dos quais diferentes pesquisadores procuraram abordar o ciclo, tentando endossar a premissa de que o próprio Huberman (2000) ponderou que este não é linear e que pode ser vivenciado por diferentes sujeitos em diferentes espaço-tempos de sua vida profissional. Brito (2011), por exemplo, chamou de "marco" as referências que os professores participantes da pesquisa apontaram como demarcadores de uma maior consolidação de sua visão de docência no ensino superior, sendo esse marco considerado pela maioria dos sujeitos como o momento de formação em nível de doutorado, pois foi o que lhes proporcionou um sentimento de autonomia na profissão. Já Isaia, Bolzan e Giordani (2007) indicaram como "movimentos construtivos" as percepções dos professores sobre a docência e estas por sua vez, nortearam as formas como os docentes se situaram e atuaram em diferentes momentos da carreira no ensino superior e que caracterizaram o momento de escolha pela docência, ressignificação da formação para nela atuar e a consciência da docência que 
reflete um engajamento dos professores nas atividades educativas, com vistas ao efetivo desenvolvimento de seus alunos, o que endossaria uma dimensão mais humana do trabalho.

Nessa mesma linha, Brito (2011), baseando-se em Cavaco (1993), também chamou de 'linhas de forças' aspectos diversos que denotam momentos de transição de uma fase para outra, provocadoras de mudanças desde a adaptação e o envolvimento em diferentes espaços no ensino superior, a pesquisa e a produtividade e o assentamento na profissão, todas elas caracterizadas, portanto, por algumas 'linhas de forças', apontadas pelos sujeitos de sua pesquisa.

De modo similar, o estudo com professores do ensino superior, especificamente do curso de Administração em uma IES privada, desenvolvido por Fontanini, Filipak e Krast (2017) teve o objetivo de caracterizar possíveis fases vivenciadas pelos professores participantes da pesquisa. A pesquisa identificou que esses docentes parecem se posicionar na carreira de modo ascendente, principalmente, pela via do fortalecimento do conhecimento pedagógico que é proporcionado, na maioria das vezes, pela integração à pesquisa, mas, contraditoriamente, pela busca por programas de formação em cursos de doutorado nem sempre na área da docência, e ainda pelo reconhecimento de si como referência numa área de estudo como um aspecto motivador.

A partir das categorias de continuidades e descontinuidades, o estudo de Biasoli (2009) também ratificou a compreensão do caráter não linear que marca o ciclo de vida profissional e, assim, analisou a construção da trajetória profissional de professores de Artes Visuais. Farias et al (2018), analisando a carreira de professores de Educação Física escolar atuantes na rede municipal de ensino de Porto Alegre, também identificou diferentes fases, que necessariamente não indicariam um movimento decadente no percurso conforme os anos se passam, mas apontam para uma maturidade na docência. Essa maturidade é construída pelas formas de entrada na carreira; a consolidação das competências profissionais e a afirmação e diversificação de ação profissional. O estudo apontou ainda para a necessidade se fazer um acompanhamento adequado do processo da aposentadoria, tanto em termos de políticas como também pela via da ampliação de novos estudos investigativos.

Sobre o eixo denominado foco em uma dimensão do ciclo, foram identificadas pesquisas que empreenderam estudos que se direcionaram para diferentes dimensões de análise do ciclo de vida profissional. Assim, o ciclo em si não foi o objeto de estudo, mas foi tomado como o contexto mais amplo, sob os quais os objetos puderam ser melhor investigados. Exemplo desse eixo foi a pesquisa de Garbin (2017) que teve as mudanças na prática pedagógica como foco do estudo, sendo analisadas a partir do contexto do ciclo de vida profissional, ou seja, a partir de diferentes momentos da vida profissional de professoras dos anos iniciais da rede pública de ensino de Curitiba. A investigação 
sistematizou que as práticas pedagógicas das professoras participantes da pesquisa são caracterizadas, em todas as fases da carreira, pela utilização de diferentes materiais didáticos, pela construção criativa das aulas e por posturas de comprometimento com a profissão, marcada também por trocas de experiências entre os pares e práticas consideradas colaborativas. Percebeu-se certa predominância de uma orientação teóricometodológica, norteada pela abordagem da escola nova, embora sejam identificados traços e influências de outras abordagens. Destacou-se ainda que há similitudes nas práticas das professoras com aspectos descritos por Huberman (2000) nas fases iniciais da carreira; porém, quanto às fases finais, foram observadas contradições em relação às características dessas fases, apontadas por aquele pesquisador (GARBIN, 2017).

Ferreira (2017) por sua vez, tomou o ciclo como pano de fundo para dar destaque para os saberes e as experiencias para se contrapor ao modelo europeu que tem norteado os estudos sobre carreira e desenvolvimento profissional docente na realidade brasileira. Já o estudo de Pitta (2018) teve como objeto as razões pelas quais professores dos anos iniciais do ensino fundamental permanecem na docência. Mesmo não podendo ter contato com as professoras que se encontrassem nas fases finais ( professoras atuantes há mais de 16 anos) - apontadas pelo ciclo descrito por Huberman (2000) - a autora chega à conclusão de que essas docentes, para permanecerem na docência, enfrentam diferentes desafios muito pelo fato de estarem convictas da escolha da profissão e pela construção de um sentimento de responsabilidade social da profissão de professor. O estudo de Pires, Alves e Gonçalves (2016) teve como objeto as percepções dos professores que não atuam no ensino superior, sobre o seu desenvolvimento profissional, chegando à conclusão de que existem diferentes percepções sobre o seu próprio desenvolvimento, de acordo com o período da vida profissional e com os níveis de ensino em que atuam. Também com o foco nas percepções de professores, a pesquisa de Timm (2018) direcionou-se a analisar o bem/mal estar docente nos processos de trabalho, ao longo de trajetórias e carreiras de professoras que atuam na Pós-graduação em Educação. Por meio de narrativas (auto)biográficas de vida ocupacional, a pesquisadora concluiu que as professoras apresentaram similaridades e singularidades em diferentes ciclos, vivenciados dada a história pessoal de cada uma, mesmo tendo idades cronológicas semelhantes quando da entrada na carreira docente, mesmo que essa entrada tenha se dado por vias bastante diferenciadas entre si.

Na mesma linha, com foco em uma dimensão do ciclo, o estudo de Rossi e Hunger (2012) buscou analisar os significados atribuídos por professores de Educação Física escolar na relação entre a formação continuada e as etapas do desenvolvimento profissional, ou seja, como refletem e se situam em movimentos de formação continuada que realizam ou não, em diferentes momentos das etapas de seu desenvolvimento profissional. O que se destacou foi o fato de os professores apresentarem necessidades formativas diferentes em cada momento profissional, refletindo, por sua vez, nas 
diferentes caracterizações elencadas pelo estudo de Huberman (2000). Também com o foco nos processos de formação continuada, Ribeiro e Vieira ( 2015) caracterizou as experiências de formação continuada de professores que atuam em instituições privadas de ensino superior à luz das fases elaboradas por Huberman (2000) e problematizou que tais fases não comportam as especificidades vivenciadas pelos sujeitos participantes de sua pesquisa, uma vez que identificou que esses sujeitos estão em constante formação, a despeito da fase da carreira em que se encontram, mesmo que não reflitam sobre os diferentes espaços e tempos em que a formação continuada pode se dar no cotidiano de seu trabalho.

Com foco nos processos formativos desenvolvidos por uma professora atuando há 30 anos como alfabetizadora, o estudo de Feller (2008) investigou os elementos que influenciaram em sua permanência por tanto tempo em classes de alfabetização. Tendo como contexto amplo de análise as fases do ciclo de vida profissional elencadas por Huberman (2000), a autora indicou que a afetividade e a reflexão foram elementos-chave para que a professora participante da pesquisa se sentisse realizada e motivada, tanto para permancer na profissão quanto mais marcadamente, em ser professora alfabetizadora, mesmo passando por diferentes fases do ciclo.

\section{Considerações finais}

Com o objetivo de analisar as publicações no Brasil que tratam dos ciclos de vida profissional na carreira docente no período de 2006 a 2019 como um processo de vivências na profissão que oportunizam movimentos de profissionalização, buscamos acessar, por meio do estado do conhecimento, pesquisas que tiveram como tema o ciclo de carreira e ou termos afins. Foi possível concluir que, conforme anunciado, há certa dispersão de termos que necessitam ficar mais claros nos estudos de modo a se compreender as diferentes dimensões de análises eleitas e as abordagens epistemológicas desenvolvidas.

Identificou-se a predominância de pesquisas a partir da subjetividade dos professores e professoras; porém, nem sempre com a clareza sobre qual perspectiva de subjetividade partia o estudo. Esse aspecto também é referendado pelo fato de, em muitos estudos, serem usados os termos experiências, vivências e correlatos, mas sem se apresentar a partir de qual conceito e ou definição se norteiam. Dessa forma, endossa-se a perspectiva de analisar a categoria vygotskiana de perejivânie como contribuição aos estudos da temática do ciclo de vida profissional. Contudo, é pertinente destacar que aqueles que assumem claramente sua perspectiva muito contribuem para a análise da realidade brasileira e, nesse sentido, tem-se Brito (2011); Alvarenga e Tauchen (2018), por exemplo. 
Ainda sobre a temática da dispersão de termos, imprescindível se torna destacar a relevância dos estudos de Isaia e colaboradores (ISAIA; BOLZAN, 2007; ISAIA et al., 2010; ISAIA e CASTRO, 2010; BUSS et al., 2008) que foram apresentados em diferentes suportes de pesquisas e nos quais se pôde perceber a clarificação de conceitos e os estudos de Brito (2011) e Ferriera ( 2017) e também a contraposição ao modelo analítico do ciclo proposto por Huberman (2000) e outros também citados, cujo aspecto analítico geral apresenta uma abordagem por fases ou etapas com destaque para a temporalidade.

Considera-se que o conjunto de estudos sobre o contexto do trabalho docente no ensino superior da realidade brasileira, com exemplos também da educação básica, ao darem destaque a elementos do trabalho enquanto categoria social, desvelando processos de intensificação, precarização e carga horária efetiva de trabalho e condições gerais de infraestrutura (estudos de TIMM, 2018; CARDOSO, 2017; 2018; FRANÇA, 2018 dentre outros) possibilitou inferir que existem elementos significativos para que se endosse a necessidade de estudar especificamente o ciclo de vida profissional no Brasil, a partir da categoria do trabalho docente, aliada às especificidades da história pessoal de cada professor. Esse último aspecto toma a história pessoal de cada professor, situada no âmbito profissional, juntamente com as implicações dos processos de profissionalização que têm sido empreendidos no contexto do capitalismo. Isso significa agregar às dimensões pessoais, culturais, sociais e cognitivas existentes um processo de trabalho humano denominado de profissão, compreendendo que este está situado em um território de disputas e que nem sempre a vivência individual pode expressar todas as determinações existentes em contraposição à função social do professor no contexto das relações de produção mais macros e na promoção de análises da interrelação das categorias objetividade-subjetividade alinhando princípios que norteiam o reconhecimento das especificidades do exercício do magistério, e as condições reais e objetivas daqueles que realizam o seu trabalho.

Os estudos de revisão de literatura apontam que os ciclos de vida profissional docente são permeados por desafios, dilemas e conquistas que repercutem no processo de como o professor se percebe e se sente no ambiente de trabalho, na busca da realização pessoal e profissional, e que, portanto, necessitam ampliar os conceitos que abordam o tema e a forma da pesquisa. Por exemplo, o conhecimento de diferentes procedimentos metodológicos e técnicas de análise que se voltam para ouvir professores que nos ajudam a responder a questões, tais como, quando se elege trabalhar com um só sujeito? ou quando um grupo de sujeitos permitirá análises mais amplas?

Referente ao objetivo da pesquisa que trata de abordar o ciclo de vida profissional nas dimensões da temporalidade e a condição do trabalho docente, observamos que as pesquisas enfatizam a questão do tempo no ciclo de vida profissional, mas carece de aprofundamento para compreensão da interação entre temporalidade e o trabalho docente. Isso é o que desafia a problematizar e realizar investigações coerentes com os aspectos 
elencados nesse estudo, e com uma matriz paradigmática crítica numa perspectiva emancipadora.

\section{Referências}

ALVARENGA, B. T.; TAUCHEN, G. Percepções e Compreensões Sobre o Ciclo de Vida Profissional e o Desinvestimento da Carreira Docente. Revista Conhecimento Online, Novo Hamburgo, v. 2, p. 25-45, jul. 2018. ISSN 2176-8501. Disponível em: $<$ https://periodicos.feevale.br/seer/index.php/revistaconhecimentoonline/article/view/12 433. Acesso em: 06 julho 2020

BARONE, T. et al. A future for teacher education: developing a strong sense of professionalism. New York, 1996.

BIASOLI, C. L. A. Docência em Artes Visuais: continuidades e descontinuidades na (re) construção da trajetória profissional. 2009. 313 f. Tese (Doutorado em Educação) Universidade Federal de Pelotas, Pelotas, 2009.

BOSI, E. Memória e Sociedade: lembranças dos velhos. 3. ed. São Paulo: Companhia das Letras. 1994. 484p.

BRITO, T. T. R. O ciclo de vida profissional dos professores de Biologia da Universidade Federal de Uberlândia: trajetórias, carreira e trabalho. 2011. 370 f. Dissertação (Mestrado em Ciências Humanas) - Universidade Federal de Uberlândia, Uberlândia, 2011.

BUSS, A. de M. et al. Professores universitários narrando suas trajetórias docentes: em busca de marcas da vida e da profissão. In: Congresso de Educação Superior, 2008, Curitiba. Anais... Curitiba: PUCPR, 2008. v. 1. p. 10477-10489.

CARDOSO, S. Ciclo de carreira docente: o que dizem as pesquisas brasileiras? Anais XIV Educere - Congresso Nacional de Educação. Formação de professores: diálogos. Curitiba, PUC-PR, 2019.

CARDOSO, S.; SILVA, M. E.; FRANCA, F. G. C. O ciclo de carreira e as condições de trabalho: Aproximações e relações possíveis. In: Encontro Nacional de Didática e Práticas de Ensino, 2018, Salvador. Anais do XIX ENDIPE, 2018.

CAVACO, M. H. Ser professor em Portugal. Lisboa: Editorial Teorema. 1993. (Coleção Terra Nostra)

ERIKSON, E. El ciclo vital completado. Buenos Aires: Paidós, 1985.

FARIAS, G. O. et al. Ciclos da Trajetória Profissional na Carreira Docente em Educação Física. Movimento (ESEFID/UFRGS), Porto Alegre, p. 441-454, jun. 2018. ISSN 19828918. Disponível em: <https://seer.ufrgs.br/Movimento/article/view/75045>. Acesso em: 
05 jul. 2020.

FELLER, E. L. Processos formativos e ciclo de vida de uma professora alfabetizadora. 2008. 123 f. Dissertação (Mestrado em Educação) - Universidade Federal de Santa Maria, Santa Maria, 2008.

FERREIRA, L. G. (2016). Desenvolvimento profissional e carreira docente: diálogos sobre professores iniciantes. Acta Scientiarum. Education, 39(1), 79-89.

FONTANINI, C. A. C.; FILPAK, S. T.; KRAST J. As fases na vida dos professores: Um estudo com professores do curso de administração em uma instituição de educação superior privada no Brasil. Revista Espacios. Vol. 38 (Nº 35) Ano 2017.

GARBIN, A. R. A prática pedagógica de professores em diferentes momentos da carreira docente. 2017. Dissertação (Mestrado em Mestrado em Educação) - Pontifícia Universidade Católica do Paraná.

GODTSFRIEDT, J. Ciclos de Vida Profissional na Carreira Docente: Revisão Sistemática da Literatura. Corpoconsciência, Cuiabá-MT, vol. 19, n.02, p. 09-17, mai/ago 2015.

GONÇALVES, J. A. A carreira das professoras do ensino primário. In: NÓVOA, António. (Org.). Vidas de professores. Porto: Porto, 1992.

HUBERMAN, M. O ciclo de vida profissional dos professores. In: NÓVOA, António. (Org). Vidas de professores. 2. ed. Porto: Porto, 2000.

ISAIA, S. M. A.; BOLZAN, D. P. V.; GIORDANI, E. M. Movimentos construtivos da docência superior: delineando possíveis ciclos de vida profissional. Anais da $30^{a}$ ANPED GT 08: Formação de Professores, 2007.

ISAIA, S. M. A.; BOLZAN, D. P.V. Compreendendo os movimentos construtivos da docência superior: construções sobre pedagogia universitária. Linhas Críticas, 14(26), 2008, p. 43-60.

ISAIA, S. M. A. Relatório de Projeto de Pesquisa CNPq. Ciclos de vida profissional de professores do ensino superior: um estudo comparativo sobre trajetórias docentes. Processo n 309235/2006-5, chamada PQ - 2006, com vigência de 2007 a 2010.

ISAIA, S. M. de A. e CASTRO, A. de M. B. de. Professores de uma IES Pública e de uma IES confessional: Comparando Trajetórias Docentes. VIDYA, v. 29, n. 1, p. 9-19, jan./jun., 2009 - Santa Maria, 2010.

JOSSO, M. C. Experiências de Vida e Formação. São Paulo: Cortez, 2004.

MARTINS, H. T. Gestão de carreiras na era do conhecimento: abordagem conceitual e resultados de pesquisa. Rio de Janeiro: Qualitymark, 2001.

MARCELO GARCIA, C. Desenvolvimento Profissional: passado e futuro. Sísifo - 
Revista das Ciências da Educação, n. 08, p. 7-22, jan./abr. 2009. Disponível em: https://dialnet.unirioja.es/imagen/xicono_articulo.png.pagespeed.ic.3BiDQzXkIu.webp Acesso em: 05 mar. 2019

MORIN, E. Ciência com consciência.8. ed. Rio de Janeiro: Bertrand Brasil, 2005.

MOROSINI, M. C. (Org.). Enciclopédia de Pedagogia Universitária. v.2. Brasília: Inep/MEC, 2006.

NASCIMENTO, J. V. do; GRAÇA, A. A evolução da percepção de competência profissional de professores de educação física ao longo de sua carreira docente. In: Anais do VI Congresso de Educação Física e Ciências dos Desportos dos Países de Língua Portuguesa, 6., 1998, La Coruña. La Coruña: INEF, 1998. Cd-Rom.

NÓVOA, A. O passado e o presente dos professores. In: NÓVOA, A. (Org.). Profissão professor. Porto: Porto, 2000.

ORTEGA Y GASSET, J. Idea de la generación. In. ORTEGA Y GASSET, J. Obras completas. 3 ed. Madrid: Ediciones de la Revista Del Occidente, 1955. p.29-54.

PINEAU, G. A autoformação no decurso da vida: entre hetero e a ecoformação. In: NÓVOA, António; FINGER, M. (Org.). O método (auto)biográfico e a formação. Lisboa: Ministério da Saúde, 2003.

PIRES, R., ALVES, M., \& GONÇALVES, T. (2016). Desenvolvimento Profissional Docente: Percepções dos Professores em Diferentes Períodos ao Longo da Vida. Revista Portuguesa de Pedagogia, 50(1), 57-78.

PITTA, P. de S. Razões que mobilizam o exercício docente nos anos iniciais da educação básica. 95F. Dissertação (Mestrado em Educação) - Universidade La Salle, Canoas, 2018

RIBEIRO, A. F. M. e VIEIRA, A. M. D. P. O Ciclo de Vida Profissional e a Formação Continuada dos Professores das Instituições Privadas de Ensino Superior em Curitiba. Anais XII Educere - Congresso Nacional de Educação. Formação de professores: diálogos. Curitiba, PUC-PR, 2015.

RIEGEL, K. Foundations of dialectical Psychology. New York: Academic Press, 1979.

ROSSI, F. and HUNGER, D. As etapas da carreira docente e o processo de formação continuada de professores de Educação Física. Rev. bras. educação física esporte [online]. 2012, vol.26, n.2, pp.323-338. ISSN 1807-5509

STROOT, S. Organizational socialization: factors impacting beginning teachers. In: SILVERMAN, Stephen.; ENNIS, Catherine. (Orgs.). Student learning in Physical Education. Champaign: Human Kinetics, 1996.

TARDIF, M. Saberes docentes e formação profissional. Petrópolis: Vozes, 2001. 325p. 
TIMM, J. W. O ciclo de vida profissional na docência no Stricto Sensu em educação: o sentido, o significado e a percepção do bem/mal-estar a partir de narrativas (auto)biográficas. Tese de doutorado. Pontifícia Universidade Católica do Rio Grande do Sul. 235f. 2018.

VYGOTSKI, L. S. Quarta aula: a questão do meio na pedologia. Tradução de Márcia Pileggi Vinha e Max Welcman. Psicol. USP. São Paulo, vol.21, n.4, 2010. Disponível em https://www.scielo.br/scielo.php?script=sci_arttext\&pid=S0103-65642010000400003

Acesso em: 10 out. 2012.

$* * *$

Recebido em: 21 mar. 2020. Aprovado em: 06 jun. 2020.

* Kátia Augusta Curado Pinheiro Cordeiro da Silva é Professora Associada da Faculdade de Educaçção e do Programa de Pós-graduação em Educação da Universidade de Brasília (UnB). Possui graduação em Pedagogia, Mestrado em Educação Brasileira e Doutorado em Educação, ambos pela Universidade Federal de Goiás, e Pós-doutorado na UNICAMP. Pesquisadora Produtividade do CNPq, coordena o Grupo de Pesquisa sobre Formação e Atuação de Professores/Pedagogos (GEPFAPe) e a coordenadora do GT-08 - Formação de professores da Anped. É vice-presidente da ANFOPE.

E-mail: katiacurado@unb.br

ORCID https://orcid.org/0000-0002-9808-4577

**Shirleide Pereira da Silva Cruz é Professora Adjunta da Faculdade de Educação e do Programa de Pós-graduação em Educação da Universidade de Brasília (UnB). Possui graduação em Pedagogia, Mestrado e Doutorado em Educação pela Universidade Federal de Pernambuco (UFPE). É formadora do Centro de Estudos em Educação e Linguagem da UFPE e pesquisadora do Grupos de Estudo e Pesquisa sobre atuação e formação do professor/Pedagogo- GEPFAPe.

E-mail: shirleidesc@gmail.com

ORCID https://orcid.org/0000-0002-4639-8400 